\title{
O uso de uma sequência didática na promoção do letramento crítico
}

\author{
Bruna Carreira da Silva e Silva \\ Universidade Federal do Rio de Janeiro \\ Marcelo Gonçalves Soares Maciel \\ Universidade Federal do Rio de Janeiro
}

\begin{abstract}
Resumo
Este trabalho tem como objetivo discutir o desenvolvimento do letramento crítico a partir de uma sequência didática aplicada em uma escola da rede pública participante do projeto PIBID (CAPES/UFRJ). Os dados foram gerados através de um questionário, e os resultados apontam para uma defasagem quanto à capacidade crítica dos alunos.

Palavras Chave: Letramento crítico, Sequência didática, PIBID.
\end{abstract}

\begin{abstract}
This paper discusses the development of students' critical literacy using a didactic sequence in a public school which participates in the PIBID(CAPES/UFRJ) project. The data were generated through a questionnaire, and the results show that the students are still not developing their critical skills properly.
\end{abstract}

Key words: Critical literacy, didactic sequence, PIBID.

\section{INTRODUÇÃO}

De acordo com as Orientações Curriculares do Ensino Médio, a escola deveria se voltar para a formação de cidadãos críticos e reflexivos. Esta afirmação se torna ainda mais característica, uma vez que os alunos estão para embarcar na vida adulta e vivem dentro de uma sociedade na qual precisam reconhecer seu papel (BRASIL, 2006).

Cada disciplina do currículo escolar, nesse sentido, contribui com noções necessárias para a prática social oferecidas para esses alunos. A língua estrangeira também se mostra participante ativa nessa formação, uma vez que tem a missão de explorar e expandir o conhecimento dos alunos ao trazer um novo universo cultural por trás de uma língua desconhecida (BRASIL, 1998).

Seguindo essa linha de raciocínio, a língua inglesa tem papel fundamental na 
atualidade como língua global. Ela tornou-se o instrumento de comunicação para as mais diversas interações profissionais e culturais, sendo estas materializadas não só através da língua escrita, mas também por intermédio oral. Não seria errôneo, portanto, admitir que a oralidade tem papel fundamental na vida dos alunos que buscam novas oportunidades depois da vida escolar (BRASIL, 1998).

No entanto, ao observar a bagagem dos alunos já formados nesse modelo, pode-se afirmar que as condições vividas pelos professores - salas lotadas e heterogêneas — não são as mais propícias para esse aprendizado (BRASIL, 1998). O letramento crítico, previsto pelas Orientações Curriculares do Ensino Médio e tido como um dos pontos fundamentais do mesmo, não vem sendo contemplado pela escola de modo geral (BRASIL, 2006).

A partir dessa defasagem, diversos campos do conhecimento conquistaram turmas de PIBID - Programa Institucional de Bolsa de Iniciação à Docência - para auxiliar alunos com dificuldades. Com a língua estrangeira não foi diferente, uma vez que a escola tem, de modo geral, privilegiado a habilidade de leitura desses estudantes — tida como a mais importante, por ser útil a eles no ingresso à universidade (BRASIL, 1998).

Nessas turmas de PIBID tem-se mais espaço e mesmo mais tempo para trabalhar as outras habilidades linguísticas, assim como também o letramento crítico dos alunos.

Dessa forma, com base na teoria de Dolz, Schnewly e Noverraz (2010), este trabalho foi desenvolvido a partir de um tema - as múltiplas inteligências — que deu origem a uma sequência didática aplicada em sala de aula para quinze alunos de PIBID, tendo em vista o desenvolvimento da capacidade reflexiva desses alunos. Com as ideias dessa sequência, foram montadas questões que testariam a criticidade dos alunos em questão - em tese trabalhada pela escola, que visa à consciência do cidadão para com seus direitos e deveres.

\section{FUNDAMENTAÇÃO TEÓRICA}

Seguindo proposta inicial, a escola deve ser responsável pela formação do cidadão consciente de seus direitos e deveres perante o meio social em que ele se encontra inserido. Nesse sentido, a instituição deve promover o pensamento crítico dos alunos, uma vez que o estudante deve ser capaz de questionar o mundo à sua volta (BRASIL, 
2006).

Apesar de tudo, por diversos motivos, a escola não contempla diversos conceitos e práticas previstas pelas Orientações Curriculares do Ensino Médio (2006). A questão do letramento crítico, por exemplo, muitas vezes é deixada de lado devido à carga e às noções que as mais diversas disciplinas precisam contemplar (BRASIL, 1998).

A língua estrangeira, muitas vezes, é tida como a disciplina responsável pela desenvoltura dessa capacidade reflexiva, uma vez que tem o dever de apresentar a variedade cultural pertencente aos países falantes da língua em questão (BRASIL, 1998). O inglês é considerado uma língua global atualmente, o que o torna ainda mais relevante para o contexto situacional dos alunos.

No ensino regular, porém, a habilidade de leitura é privilegiada - para os alunos que ingressassem no ensino superior e necessitassem ler textos na língua inglesa - já que a escola não dá conta das outras competências linguísticas. Atualmente, a capacidade de se comunicar na língua-alvo - mais do que simplesmente a habilidade oral — seria mais importante, tendo em vista o mundo globalizado em que os alunos irão viver.

Para suprir essa necessidade e dar oportunidade aos alunos interessados, turmas PIBID - Programa Institucional de Bolsa de Iniciação à Docência — foram criadas. Esse ambiente de aulas se dá no contraturno, com professores graduandos da Universidade Federal do Rio de Janeiro. Com esses estudantes, a possibilidade de praticar as habilidades linguísticas é viável, além do espaço permitir o trabalho crítico e reflexivo.

Consequentemente, nas aulas ministradas, trabalhou-se com o conceito de Sequência Didática desenvolvida por Dolz, Noverraz e Schnewly (2010). Essa organização é constituída por uma certa introdução ao tópico, que leva a uma produção inicial. Após essa produção, são propostas diversas atividades por meio das quais o aluno pode praticar e aprender outras noções, construídas a partir do que eles já interiorizaram. Ao fim da sequência, os alunos passam por uma última produção, onde tudo que ele aprendeu é posto em prática.

Essa estrutura, nesse sentido, permitiu construções de atividades interligadas a partir de um tema, entendendo a língua como prática social (BRASIL, 1998). Nesse modelo, era possível trazer para a sala de aula discussões relevantes para o grupo, além de explorar diversos gêneros a depender da situação. 
Não menos importante, um desenvolvimento do letramento crítico dos alunos se mostrou pertinente, uma vez que existe o objetivo de se formar cidadãos. Entende-se aqui o letramento crítico como um estágio superior à questão da mera leitura ou da interpretação. Essa fase posterior seria quando um aluno conseguiria não só entender o texto, mas também pensar e refletir acerca dele, pensando e repensando sua própria realidade (NICOLAIDES \& TILIO, 2011; BRASIL, 2006). Sendo assim, com o intuito de se atingir esse ponto, diversas questões reflexivas foram postas em prática a partir das sequências produzidas, e os alunos obtiveram situações com as quais podiam se expressar livremente sobre os questionamentos levantados.

Finalmente foi aplicado para este trabalho um questionário, no qual os alunos deveriam ressignificar o conteúdo visto em sala de aula e dar a sua opinião acerca do tema de uma sequência didática: o tema das múltiplas inteligências. Nesse questionário foi avaliada a capacidade do pensar crítico e reflexivo de quinze alunos participantes, estimulada já previamente em sala de aula.

\section{METODOLOGIA}

Com a disponibilidade e o tempo hábil para diversas atividades do gênero, a sequência didática se encaixou no projeto PIBID - Programa Institucional de Bolsa de Iniciação à Docência — de forma a integrar o ensino com temas relevantes aos alunos desse contexto e oportunidades para que cada um pudesse se expressar quando desejado (BRASIL, 1998).

A pesquisa foi realizada numa escola pública estadual, participante deste projeto, localizada na zona sul do Rio de Janeiro. Essas turmas PIBID são viabilizadas pela CAPES, e os estudantes - que se encontravam no primeiro e no segundo anos do ensino médio - assistiam a aulas no contraturno - alunos da manhã estudavam à tarde e viceversa - com professores que são obrigatoriamente graduandos da UFRJ.

Como boa parte desses alunos não possuía um grande conhecimento da língua inglesa, optou-se por aulas de nível básico. Nessas aulas, mesmo que determinados alunos fossem mais avançados, eles poderiam ajudar os alunos iniciantes. Uma vez que o modelo da aula era criado a partir de temas, alunos com mais desenvolvimento linguístico não eram necessariamente excluídos, considerando a relevância do tópico e a 
contribuição indispensável que era proporcionada por eles.

Dessa forma, foi desenvolvida uma aula na qual os alunos lidariam com o tema das múltiplas inteligências. No decorrer das atividades, os alunos entenderiam o conceito das múltiplas inteligências, aplicariam estas a si mesmos, a pessoas famosas e suas profissões, além de explorar o tipo de inteligência que se adequaria mais a uma ou outra área de trabalho.

Nessa aula, os alunos tiveram a oportunidade de assistir a vídeos sobre o tópico além do trecho inicial do filme "Vida de Inseto" — e também receberam uma folha com a sequência didática em si, composta por diversas atividades que eles deveriam realizar durante a aula (cf. Anexo).

Na primeira atividade, foram apresentadas diversas imagens de pessoas famosas, presentes na realidade dos jovens. Inicialmente, na parte introdutória do tópico, foi perguntado a eles quem eram aquelas pessoas e no que elas trabalhavam - além de um questionamento constante sobre estes serem inteligentes ou não (cf. Anexo). Dessa forma, os alunos começaram a direcionar o pensamento para esse campo e já puderam interagir utilizando a língua-alvo.

Após esse primeiro momento, os alunos de fato foram introduzidos ao conceito das múltiplas inteligências, elaborado por Gardner. Num segundo momento, os estudantes conheceram cada inteligência e sua específica descrição, o que os ajudou a definir melhor as áreas de cada pessoa na primeira atividade (cf. Anexo). Além das informações promovidas pelas atividades na folha recebida por eles, os estudantes também assistiram a um vídeo sobre as inteligências, no qual eles poderiam associar as imagens aos nomes já aprendidos.

Posteriormente, como os alunos lidaram com cada descrição, já tinham base suficiente para se identificarem no tópico. Nessa fase, os alunos pensaram no que gostavam de fazer e no que eram bons e, assim, foi pedido a eles que pensassem em suas próprias inteligências e explicassem porque se encaixavam nelas (cf. Anexo).

Por fim, os alunos foram introduzidos a mais profissões na língua estrangeira. Essas áreas deveriam ser encaixadas de acordo com a inteligência — ou inteligências mais apropriada(s) (cf. Anexo). Esse ponto da sequência foi crucial no sentido que remetia a uma das perguntas que geraram os dados para este trabalho. 
Como última atividade, ainda, os alunos assistiram a um trecho do filme "Vida de Inseto", no qual o personagem principal, Flik, é inventor e é constantemente repreendido por suas ideias inovadoras. Nesse último momento, os alunos foram levados a refletir sobre esse personagem e seu contexto situacional, além de também questionarem se já foram - ou se pelo menos já se sentiram — excluídos socialmente (cf. Anexo).

A partir dessa ideia, então, a teoria das múltiplas inteligências deixou espaço para que os alunos entendessem a si mesmos e pudessem perceber se a profissão desejada para o futuro era de fato algo plausível. Da mesma forma, eles tiveram oportunidades para inferir que não existia uma inteligência melhor que a outra, mas inteligências diferentes que cada um poderia desenvolver durante a vida.

Por meio dessa atividade houve espaço para que os alunos questionassem, por exemplo, o fato da mídia privilegiar determinadas profissões, além de poderem enxergar como a exclusão social de determinadas pessoas poderia estar ligada à sua inteligência como no trecho do filme "Vida de Inseto", exibido em sala de aula.

Consequentemente, os estudantes puderam refletir sobre o tema e suas próprias escolhas, bem como ressignificar os conceitos de autonomia vistos previamente - esta autonomia sendo vista como algo a ser estimulado tanto quanto a criticidade. Vale ressaltar que o conceito de ser autônomo refere-se a capacidade do aluno de tomar para si a responsabilidade pelo seu próprio aprendizado (NICOLAIDES \& TILIO, 2011). Também houve espaço para que o letramento crítico fosse estimulado, uma vez que os alunos vão à escola diariamente e espera-se a fomentação do mesmo.

A fim de testar essa capacidade e mesmo de desenvolver o letramento crítico, foi aplicado um questionário após a aplicação da sequência didática. Esse questionário foi respondido em aula por cerca de quinze alunos de uma escola pública do Rio de Janeiro, dos turnos da manhã e da tarde, e participantes do projeto PIBID.

Algumas perguntas do questionário direcionavam-se para reflexões mais pessoais, como qual ou quais seriam as inteligências mais desenvolvidas de cada um e qual ou quais seriam as profissões que estes gostariam de seguir — e se estas estavam ligadas às habilidades citadas anteriormente. Outras perguntas focavam mais especificamente o contexto do trecho do filme assistido pela classe - sobre qual dos personagens seria o mais inteligente e mesmo se os alunos já haviam se sentido excluídos como o personagem 
principal. Uma das perguntas, ainda, relacionava diretamente os famosos da primeira atividade (cf. Anexo) com a ideia de uma pessoa ser mais inteligente que a outra.

A partir das respostas dos alunos - chamados aqui de alunos 1, 2, 3 e 4 - foram selecionados cerca de quatro excertos, onde diferentes alunos expressaram suas opiniões e reflexões sobre o tema abordado pela sequência didática. Vale também ressaltar que, para a coleta dos dados, deu-se maior atenção a uma pergunta específica - a que questionava quem seria o mais inteligente dos famosos apresentados.

Assim, este trabalho se direcionou para uma pesquisa qualitativa de base interpretativa, realizada no segundo semestre em que o projeto atuava na escola. Com a triangulação de questões, buscou-se analisar a capacidade crítica e reflexiva dos estudantes, bem como sua capacidade autônoma quanto ao tema escolhido.

\section{RESULTADOS E DISCUSSÃO}

A língua estrangeira, como dito anteriormente, tem um papel formador dentro da escola como qualquer outra disciplina. Além disso, ela tem o dever de explorar diferentes contextos e, assim, ampliar o conhecimento de mundo dos alunos, atentando para os aspectos culturais evidentes nessa língua-alvo (BRASIL, 2006).

O tema das múltiplas inteligências possibilitou um leque de atividades construídas e estruturadas numa sequência didática (DOLZ, NOVERRAZ \& SCHNEWLY, 2010). Nessa sequência, os alunos puderam identificar as inteligências de pessoas famosas tais quais as deles próprios, além de lidar com um novo vocabulário de profissões na língua inglesa.

Os alunos, seguindo essa linha, trabalharam o tema escolhido e puderam fixar o conteúdo de forma significativa, uma vez que falaram de si mesmos, experienciaram exemplos a partir de um vídeo e discutiram impressões sobre as múltiplas inteligências. Dessa forma, um questionário foi elaborado para que os alunos demonstrassem sua capacidade de extrapolar o significado exposto em aula.

A partir do questionário elaborado, os alunos conseguiram entender o conteúdo da aula de modo geral, ao aprender as características de cada inteligência, interpretando os significados dados (cf. Anexo). Ao atingir esse determinado ponto, os alunos passaram do primeiro estágio do letramento, uma vez que não se prenderam apenas ao que estava 
escrito.

Em outras questões apresentadas, porém, a maior parte dos alunos não atingiu o outro estágio, o de letramento crítico. Ao assistirem ao vídeo, os alunos associaram a "melhor" inteligência ao personagem principal. Ao serem perguntados sobre quais famosos seriam os mais bem sucedidos, os estudantes citaram exemplos que associavam a remuneração financeira a uma boa profissão e um bom futuro, como demonstra o gráfico e o exemplo abaixo.

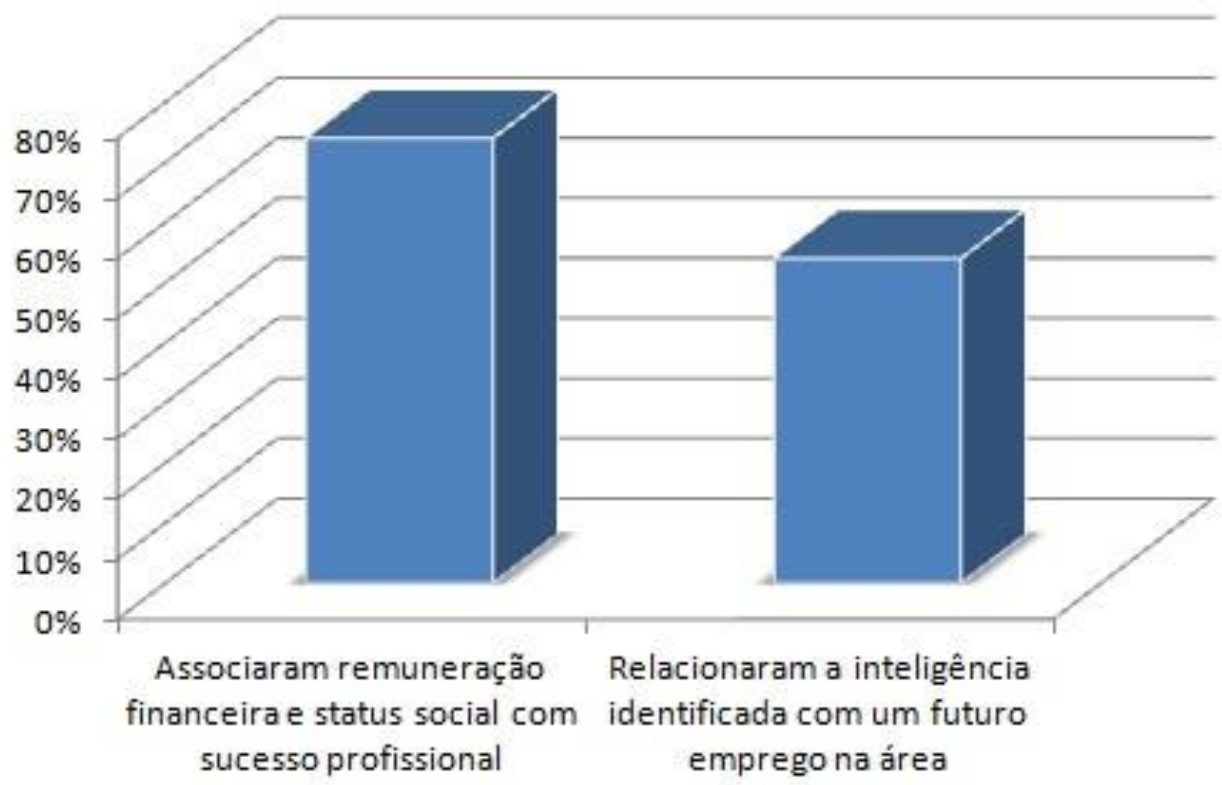

Na minha opinião é o Messi. Porque ele é um bom jogador e o salário dele é muito alto e ele já foi convocado para vários times de futebol e foi o melhor do mundo (ALUNO 1).

Além do retorno financeiro ser considerada uma coisa importante para uma grande parte dos adolescentes que responderam o questionário, o prestígio e o status social também se mostraram fatores importantes na escolha da profissão, como é visto no exemplo adiante.

Oscar Niemeyer. Porque é uma profissão que acaba emocionando e conquistando outras pessoas (ALUNO 2).

Alguns alunos foram um pouco mais críticos ao pensar em feitos importantes para o mundo em que vivem, e assim citaram exemplos mais voltados para uma perspectiva de 
contribuição social que determinado famoso proporcionou.

Talvez de um ponto de vista popular, os mais bem sucedidos seriam Leonel Messi e William Bonner, mas de uma visão particular, os mais bem sucedidos seriam Howard e Lula, porque eles descobriram/fizeram coisas que mudaram vidas (ALUNO 3).

Um aluno em particular ainda conseguiu associar a questão da contribuição social com a proposta da última atividade da sequência, que envolvia o trecho do filme "Vida de Inseto". Nesse trecho, o personagem principal era vítima de uma certa exclusão social devido às suas ideias inovadoras.

O presidente Lula. Porque ele conseguiu mudar muitas coisas no nosso país mesmo que todos não acreditassem nele (ALUNO 4).

De uma forma geral o tema das múltiplas inteligências se mostrou bastante produtivo, no sentido de que foi possível explorar diversas concepções impostas pela sociedade compartilhada pelos alunos. Porém, a maior parte dos aprendizes não alcançou o objetivo da sequência: chamar a atenção deles para o fato de que não existem pessoas mais inteligentes, mas sim existem pessoas com inteligências diferentes, algumas mais desenvolvidas que outras.

\section{CONSIDERAÇÕES FINAIS}

Com o tema das múltiplas inteligências, foi desenvolvida uma sequência didática (DOLZ, NOVERRAZ \& SCHNEWLY, 2010) através da qual seria observado o desenvolvimento do letramento crítico em alunos do projeto PIBID de língua inglesa. O tema escolhido permitia que os alunos transpusessem a sua própria realidade no questionário, por exemplo, ao falar da decisão para o vestibular, que se encontra num futuro próximo (BRASIL, 1998).

Acredita-se que o papel da escola na vida do aluno seria não só de prepará-lo para a fase do vestibular, tida como uma das mais importantes após a escola, mas também de prepará-lo para a vida em sociedade. Dessa forma, faz-se necessário um trabalho reflexivo quanto à cidadania, considerando os direitos e deveres do cidadão perante a sociedade em que ele reside. (BRASIL,2006).

A língua estrangeira tem função crucial nessa formação cidadã, uma vez que 
oferece novos recursos a esses alunos - o de conseguir expandir barreiras sociais, por exemplo, ou mesmo de ajudá-lo numa futura oportunidade de emprego (BRASIL,2006). Aprender uma língua adicional significa dar oportunidades aos estudantes de escolas públicas, e até mesmo de estimulá-los quanto ao seu desenvolvimento autônomo (NICOLAIDES \&TILIO, 2011).

A análise dos dados, porém, parece mostrar que os alunos ainda não estão, de modo geral, alcançando esse estágio de letramento crítico. Os questionários apresentaram respostas nas quais os alunos eram capazes de interpretar as questões acerca do tema e ainda se identificar com ele, mas os estudantes não foram capazes de fazê-lo de modo crítico e reflexivo, trazendo os conceitos aprendidos para sua própria realidade e, mais importante, questionando-os.

Julga-se portanto que, de modo geral, ao pensar na atividade como um todo e no intuito de demonstrar a importância de cada inteligência, a consciência crítica parece ainda não ter ganhado o seu devido espaço na escola como um todo. Acredita-se, dessa forma, que uma nova postura da instituição seria necessária para uma melhor formação de adultos mais reflexivos e participantes quanto às questões sociais.

\section{REFERÊNCIAS}

BRASIL. Ministério da Educação, Secretaria de Educação Básica. Orientações curriculares para o ensino médio. Volume 1: Linguagens, códigos e suas tecnologias. Brasília, 2006.

Disponível em:http://portal.mec.gov.br/seb/arquivos/pdf/book_volume_01_internet.pdf. Acesso em 04/07/2010.

BRASIL. Ministério da Educação, Secretaria de Educação Fundamental. Parâmetros curriculares nacionais: terceiro e quarto ciclos do ensino fundamental: língua estrangeira. $\quad$ Brasília, $1998 . \quad$ Disponível em http://portal.mec.gov.br/seb/arquivos/pdf/pcn_estrangeira.pdf. Acesso em 09/02/2013.

DOLZ, J.; NOVERRAZ, M.; SCHNEWLY, B. [2004] Sequência didática para o oral e a escrita: apresentação de um procedimento. In: SCHNEWLY, B; DOLZ, J. Gêneros orais e escritos na escola. 2 ed. Campinas: Mercado de Letras, 2010.

NICOLAIDES, C.; TILIO, R. O material didático na promoção da aprendizagem autônoma de línguas por meio do letramento crítico. IN: SZUNDY, P. et. al. (Orgs.) Linguística Aplicada e sociedade: ensino e aprendizagem de línguas no contexto 
brasileiro. Campinas: Pontes, 2011.

\section{OS AUTORES}

Bruna Carreira da Silva e Silva, graduanda, Universidade Federal do Rio de Janeiro E-mail: brunacarreirads@gmail.com

Marcelo Gonçalves Soares Maciel, graduando, Universidade Federal do Rio de Janeiro E-mail: marcelomaciel.lfl@ gmail.com 


\section{ANEXO}
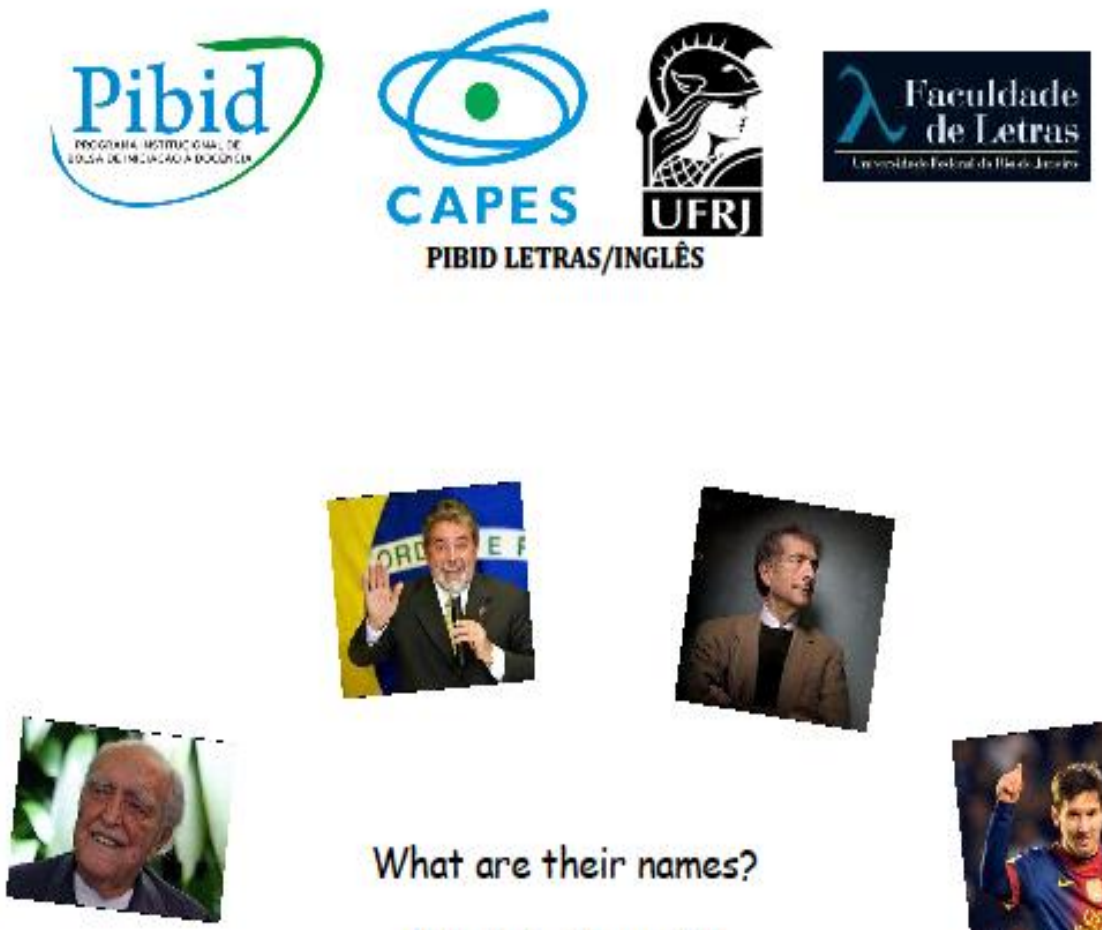

What are their names?

What do they do?
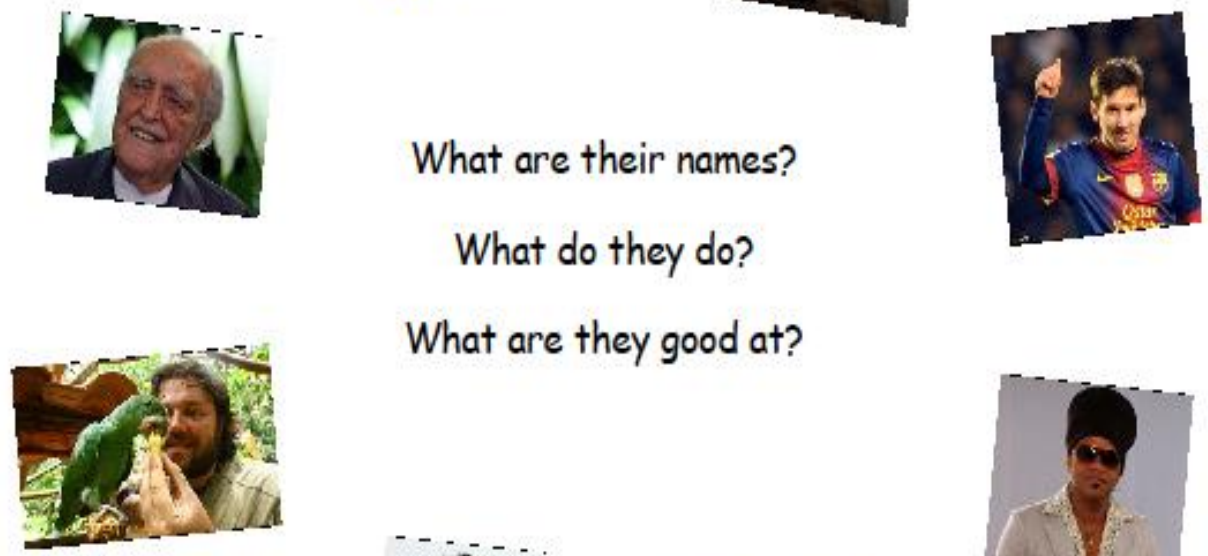

What are they good at?
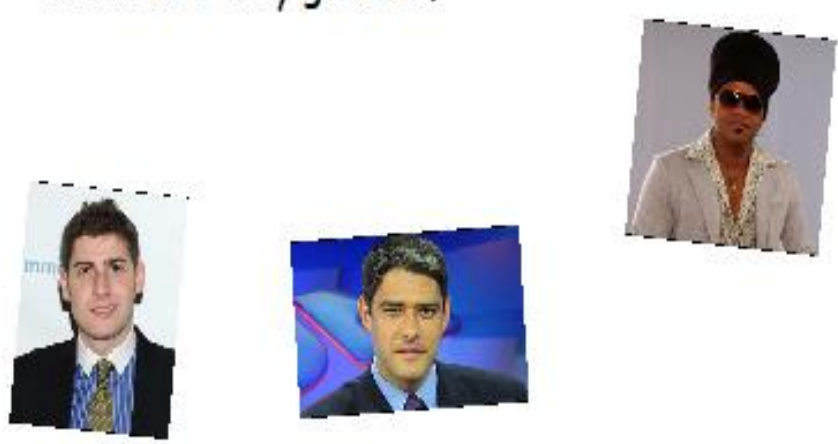


\section{Multiple Intelligences}

Based on Howard Gardner's Theory

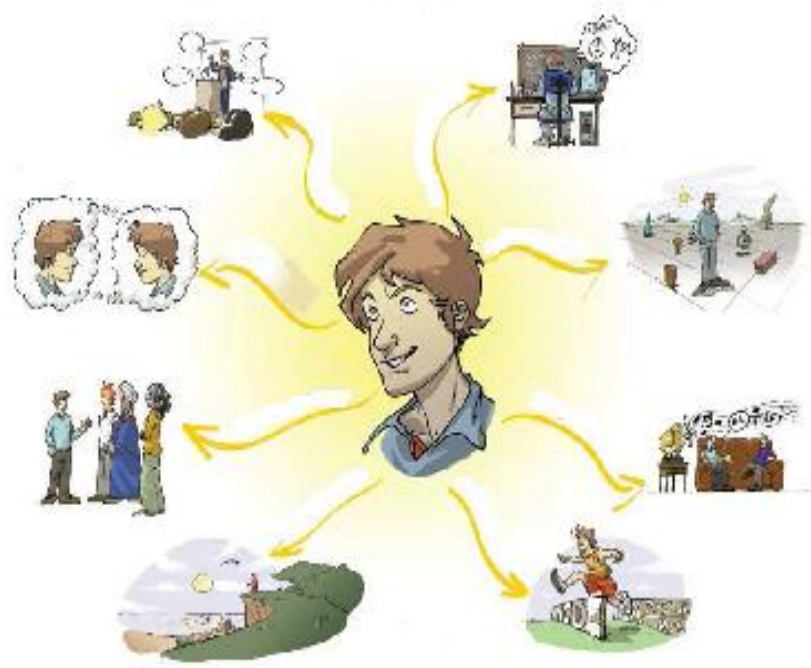

A. What the video and math the columns
a. Bodily-kinesthetic
( ) These people learn best by working with others. They work well in groups, they communicate well and really understand other people's feelings.
b. Verbal Linguistic
( ) These people learn best by getting up and moving around. They are usually good at sports, dance and might like acting, performing or building things.
c. Logical Mathematical
( ) These people learn best by reading, taking notes or listening. They are very good with all kinds of words, spoken or written.
d. Visual Spatial
( ) These people prefer to work alone. They have good understanding of themselves. They understand their own feelings and motivations.
e. Interpersonal
( ) These people enjoy singing, playing instruments and composing music.
f. Naturalistic
( ) These people are often very artistic and they are also good at solving puzzles.
g. Musical
( ) These people are sensitive to the world around them. They learn best when they can make connections with the nature.
h. Intrapersonal
( ) These people are really good at working with numbers. They are logical, enjoy finding patterns and problem solving.

B. Go back to the first page and check their most developed intelligence. 
C. Think about the many things you are good at. In your opinion, which of the intelligences studied best describes yourself? Discuss with your group

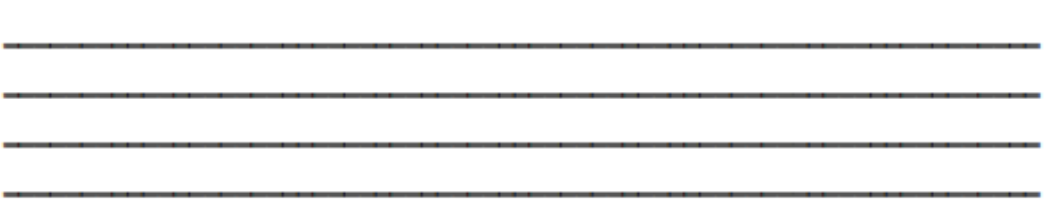

D. Match the jobs in the box bellow with the corresponding intelligence.

accountants - actor - architect - athlete - botanist - composer - counselor DJ - engineer - entrepreneur - environmentalist - farmer - firefighter journalist - lawyer - musician - novelist - painter - politician - programmer researcher - salesperson - sculptor - language teacher

\begin{tabular}{|c|c|c|c|c|c|c|c|}
\hline $\begin{array}{c}\text { Bodily- } \\
\text { kinesthetic }\end{array}$ & $\begin{array}{c}\text { Verbal } \\
\text { Linguistic }\end{array}$ & $\begin{array}{c}\text { Logical } \\
\text { Mathematical }\end{array}$ & $\begin{array}{c}\text { Visual } \\
\text { Spatial }\end{array}$ & Interpersonal & Naturalistic & Musical & Intrapersonal \\
\hline & & & & & & & \\
\hline & & & & & & \\
\hline & & & & & & & \\
\hline
\end{tabular}

E. Let's watch a part of A Bug's Life movie. What are the intelligences you can notice?

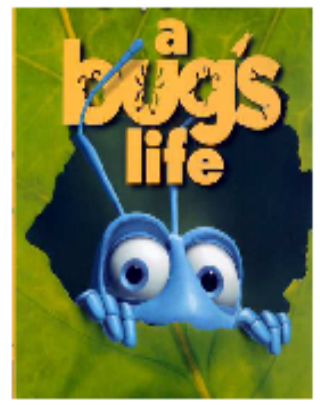

